\title{
Chemigation Equipment and Techniques for Citrus ${ }^{1}$
}

\section{Brian Boman, Sanjay Shukla, and Dorota Haman² \\ Introduction}

Chemical application through irrigation systems is called chemigation. Chemicals used can include a variety, such as fertilizer, insecticides, fumigants, and soil amendments. Chemicals can be any substance which is intended for agricultural purpose. Some of these chemicals are termed as toxic chemicals and include pesticides whose labels bear the signal words "Danger" and/or "Poison."

Chemigation has been practiced for many years, especially for fertilizer application, which is referred to as fertigation. However, other chemicals are also being applied through irrigation systems with increasing frequency. The primary reason for chemigation is economy. It is normally less expensive to apply chemicals with irrigation water than by other methods. The other major advantage is the ability to apply chemicals only when needed and in required amounts. This "prescription" application not only emulates plant needs closer than traditional methods but also minimizes the possibility of environmental pollution. Chemigation facilitates application of relatively smaller amounts of chemicals depending on the plant needs compared to one-time application of large quantities that are subject to leaching losses if heavy rainfalls follow applications. Therefore, chemigation reduces adverse environmental impacts in addition to saving the time and money needed to reapply the materials.

\section{Chemigation Safety}

Chemigation safety is an essential component of a good chemigation program. Chemigation safety can be divided into mechanical and chemical categories. While mechanical components include the devices for preventing chemical backflow, chemical spill, and injection of chemical without irrigation water flow, chemical safety for chemigation includes measures such as following manufacturers' guidelines.

\section{Backflow Prevention}

Currently, Florida state law requires that backflow prevention equipment be installed and maintained on irrigation systems in which chemicals are injected for agricultural purposes (Figure 1).

The rules governing the installation of backflow prevention devices are found in Section 487.055 of

1. This document is Circular 1403, one of a series of the Agricultural and Biological Engineering Department, Florida Cooperative Extension Service, Institute of Food and Agricultural Sciences, University of Florida. Publication date: July 2004. Visit the EDIS Web site at http://edis.ifas.ufl.edu.

2. B. J. Boman, Associate Professor, University of Florida, Indian River Research and Education Center, Ft. Pierce, FL.; S. Shukla, Assistant Professor; Southwest Florida Research and Education Center, Immokalee, FL 34142; and Dorota Haman, Professor, University of Florida, Agricultural and Biological Engineering Department, Gainesville, FL 32611.

Use Pesticides Safely. Read and follow directions on the manufacturer's label.

The Institute of Food and Agricultural Sciences (IFAS) is an Equal Employment Opportunity - Affirmative Action Employer authorized to provide research, educational information and other services only to individuals and institutions that function without regard to race, creed, color, religion, age, disability, sex, sexual orientation, marital status, national origin, political opinions or affiliations. For information on obtaining other extension publications, contact your county Cooperative Extension Service office. Florida Cooperative Extension Service / Institute of Food and Agricultural Sciences / University of Florida / Larry R. Arrington, Interim Dean 
the Florida Statute. The rules relating to backflow protection were designed to protect the surface and groundwater resources of the state.

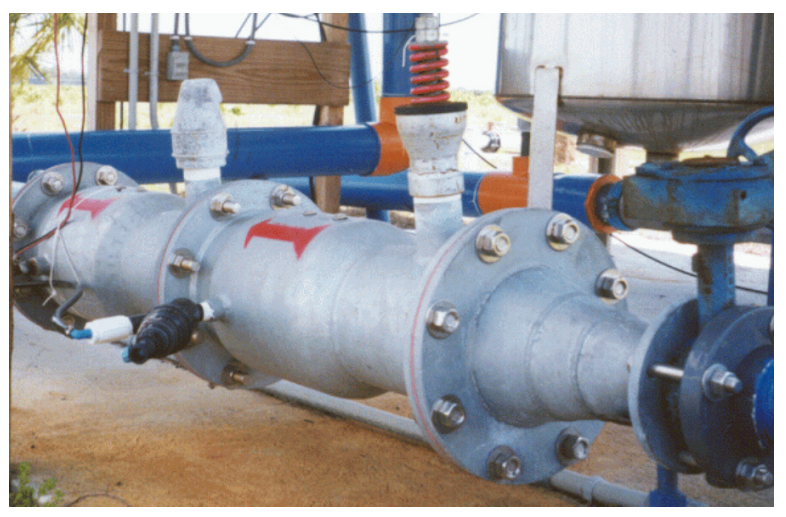

Figure 1. Typical backflow prevention device with vacuum breaker, check valve, and low pressure drain.

The possible dangers in chemigation include backflow of chemicals to the water source causing contamination and water backflow into the chemical storage tank. Backflow to the storage tank can rupture the tank or cause overflow, contaminating the area around the tank and possibly contaminating the water source. Safety equipment is available which, when properly used, will protect water supply as well as the purity of the chemical in the storage tank.

Once the problems of contamination with chemicals are solved, the risk of liability in chemigation is not much greater than the risk from the field use of chemicals applied by other means. For technical reasons such as reduced wind drift, rapid movement into the soil, and high dilution rates, chemigation could result in less risk of liability than the traditional methods of chemical application, if proper backflow prevention and other safety devices are used. An antisyphon device is a safety measure used to prevent backflow of a mixture of water and chemicals into the water supply.

\section{Safety Equipment}

The functions of the safety equipment components are to prevent contamination of ground and surface waters by the applied chemicals. The devices incorporate ways to minimize spills and operator hazards. Table 1 lists the commonly required devices, their purpose, and their location. Any irrigation system designed or used for the application of chemicals shall be equipped with the following components:

\section{Check Valve}

A functional check valve located in the irrigation supply line between the irrigation pump and the point of injection of chemicals is required. It should be installed so that it is no more than 10 degrees from the horizontal. The check valve will prevent water from flowing from a higher elevation or pressure in the irrigation system back into the well or surface water supply. It will also prevent water from being siphoned back to the water source. Thus, water with chemicals cannot flow back into the water supply. A single antisyphon device assembly (Figure 2) can be used for those systems where nontoxic chemicals, such as fertilizers, will be injected.

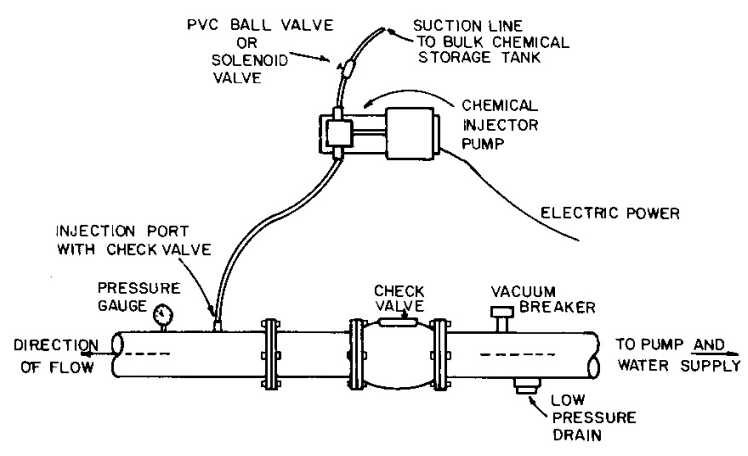

Figure 2. Backflow requirements for systems where nontoxic chemicals will be injected.

A double antisyphon device assembly (Figure 3) is required for systems where toxic chemicals will be injected. The double antisiphon device should be such that the function of each device in the double assembly system can be checked independent of each other to insure effectiveness of the system.

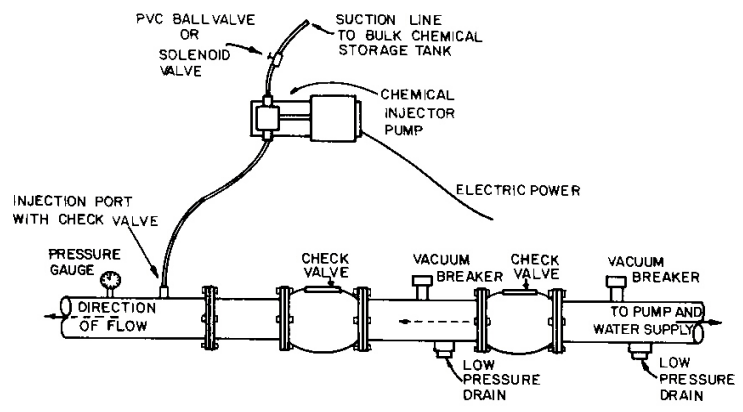

Figure 3. Backflow requirements for systems where toxic chemicals will be injected. 


\section{Drain}

A low pressure drain (Figures 2 and 3) with an orifice size of at least 3/4-inch in diameter is required. State law requires it to be located on the bottom of the horizontal pipe between the check valve and the water source. It must be located so that the water flow does not drain back to the water source. It must be level, must not extend beyond the inside surface of the pipe, and the outside opening of the drain must be above grade. A clearance of two inches between the drain and ground surface is required to assure that the drain will operate freely.

\section{Vacuum Breaker}

A vacuum breaker should be installed on the top of the horizontal pipe between the check valve and the irrigation pump, and opposite to the low pressure drain (Figure 2 and Figure 3). The vacuum breaker needs to have an orifice size of at least 3/4-inch in diameter, and must be located upright and above the irrigation pipe so that it functions effectively. The vacuum breaker will allow air to enter the pipe when pumping stops so that water flowing back to the pump will not create a suction, drawing additional water and chemicals from the irrigation system with it.

\section{Chemical Check Valve}

A functional check valve on the chemical injection line is required. If injector pumps are used, they need to be installed so that when water flow ceases, the injector pumps will not operate. In addition, a method should be provided for positive shut off of the chemical supply when the injection system is not in use. If the injector pump is mechanically driven (from a drive belt with an engine-driven pump (Figure 4), or by water flow in the irrigation system), the power supply interconnection is not needed. In these cases, when the engine stops, the injector pump will also stop.

When the chemical injector pump is electrically driven (Figure 5), its electrical circuit must be interconnected with that of the irrigation pump's electrical circuit to assure that it stops when the irrigation pump stops.

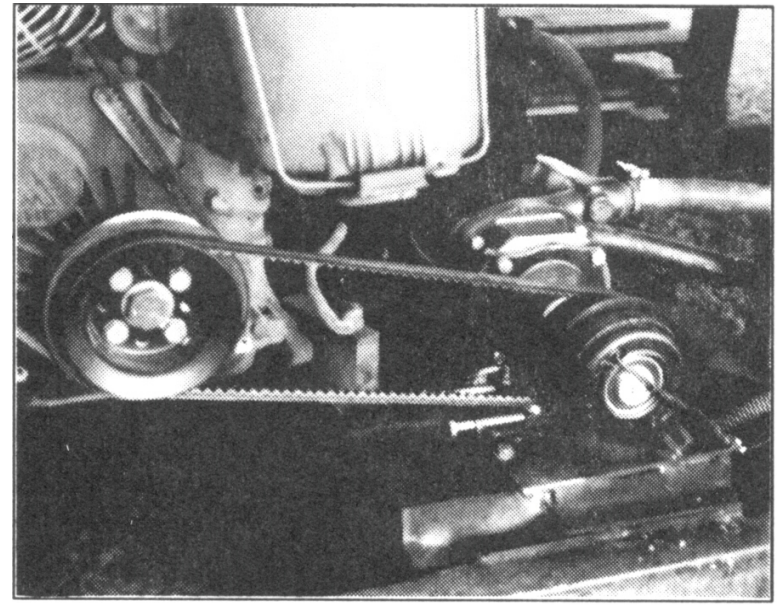

Figure 4. Engine-driven injection pump not requiring interconnect shutoff.

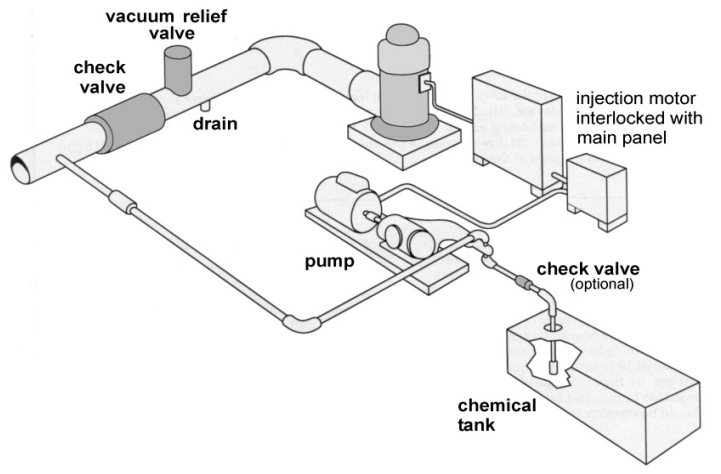

Figure 5. Requirements for electric injection pump. Note that for toxic chemicals, double backflow prevention is required.

The injector pump can also be controlled using a pressure switch or flow switch that automatically disconnects power to the injection pump when pressure or flow is discontinued in the irrigation system. These precautions assure that the chemical injector pump does not continue to inject into an empty irrigation pipeline, or worse, backwards into the water supply.

Only a spring-loaded switch, which requires the presence of an operator to engage the switch, is permissible. Spring-loaded electrical switches can be used for testing and calibration of the chemical injection pump when the irrigation pump is not operating. A multi-position switch with automatic and manual operation positions is not permissible, because it would be possible for the operator to accidentally leave the switch in a manual operation position and override its safety function. 
If chemicals are injected by means other than electric injector pumps, interconnected power supplies are not required. However, all the other backflow prevention devices are still required.

\section{Storage Tank Lines}

A check valve on the chemical injection line must be used to prevent water flow backwards from the irrigation system to the chemical storage tank. This precaution will prevent dilution of the chemical by the irrigation water. It will also prevent possible rupture or overflow of the chemical storage tank and pollution of the surrounding area.

If chemical injection pumps are used, chemical injection line check valves are typically spring-loaded and require a relatively large pressure to allow fluid to flow through them. These valves only permit flow which is a result of the high pressure generated by the pump. When the injector pump is not operating, chemicals will not leak due to the small static pressure created by the chemical level in the storage tank.

A valve must be provided for positive shutoff of the chemical supply when the injection system is not in use. This device can be a manual gate valve, ball valve, "normally closed" automatic valve, or other positive shutoff valve. The valve must be installed near the bulk chemical storage tank, on the suction side of the injection pump if an injection pump is used. It must be open only when the injector pump is operating.

An advantage of using an automatic valve is that it will shut off the chemical supply automatically when the injector pump shuts off. A disadvantage is that corrosive chemicals may cause the valve to fail to operate after a period of time. A PVC ball valve or gate valve will be less affected by corrosion; however, it will require manual operation. A good practice is to install both the manual and automatic valves. A manual valve located at the chemical tank will provide positive shutoff of chemicals when the irrigation system is not in use. All check valves, low pressure drains, and vacuum breaker should be maintained free of corrosion or other buildup at all times during operation of the system.

\section{Other Backflow Requirements}

Some counties and municipalities have backflow prevention regulations which may be more restrictive than state law. All public water supply systems have more restrictive requirements. The Florida Department of Environmental Protection (FDEP) has regulations concerning the usage of chemical storage tanks.

Compliance with the state law governing backflow prevention from irrigation systems does not alleviate the need to comply with other regulations which may apply. Rather, the state law should be considered to be only the minimum backflow prevention requirements for irrigation systems in Florida.

\section{Chemical Storage Tanks and Containment Structures}

Chemical storage tanks must be located in an area that is remote from the well site or surface water supply. Tanks should also be sloped so that contamination of the water supply will not occur in case of tank rupture or spill.

The chemical supply tank should be constructed of material that will withstand the corrosive chemicals stored in it. Some chemicals and tank materials are subject to degradation by sunlight; therefore, chemical tanks are often painted to exclude sunlight. In some cases, the chemical tank will need to be diked to contain the chemical in the event of a tank failure. State law requires chemical tanks to be placed in containment structures (or dikes) if hazardous chemicals such as pesticides are stored (Figure 6 and Figure 7).

Containment can be achieved by construction of a water-tight concrete pad with concrete block walls sufficiently large to hold 1.5 times the capacity of the chemical tank in the event of tank failure. Soil liners can be used under the tanks in permeable soil areas or where toxic chemicals are being used.

The size of the supply tank should be at least large enough to contain the entire chemical for one injection for the entire area. The volume of the tank can be determined by: 


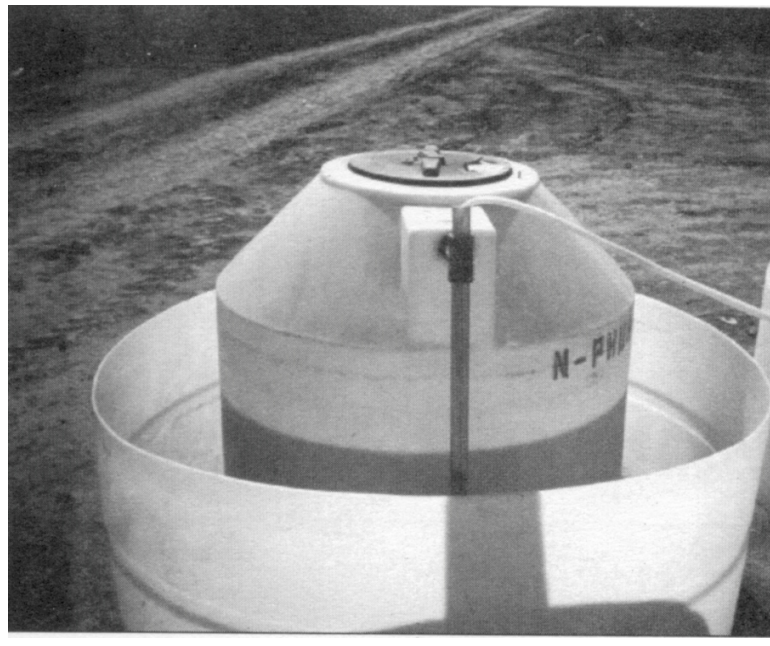

Figure 6. Polyethylene containment tank.

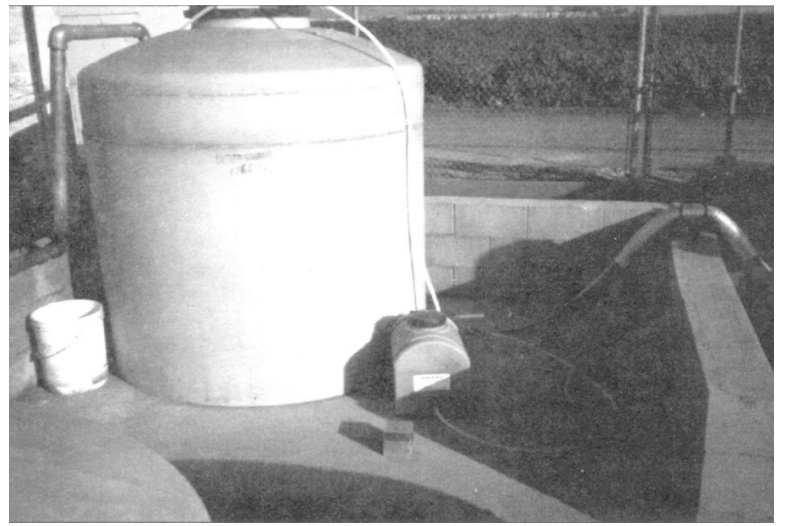

Figure 7. Concrete containment area.

$\mathrm{V}=(\mathrm{r} \times \mathrm{A} \times \mathrm{n}) /(\mathrm{c} \times \mathrm{d})$

Eq. 1

where,

$\mathrm{V}=$ volume (gallons),

$\mathrm{r}=$ rate of application $(\mathrm{lbs} / \mathrm{ac})$,

$A=$ area to be fertigated (acres),

$\mathrm{n}=$ number of applications between tank fillings,

$\mathrm{c}=$ concentration of fertilizer source $(\mathrm{N}-\mathrm{P}-\mathrm{K}$, decimal),

$\mathrm{d}=$ density of fertilizer material (lbs/gal).

To accommodate dead storage in the bottom of the tank, $10 \%$ additional storage should be added to the above calculated volume.
Example: Determine the chemical tank size required for a 100-acre citrus block given the following criteria: sufficient storage for two fertigations, application rate per fertigation is $6 \mathrm{lbs} . \mathrm{N}$ per acre. Fertilizer material is a 9-2-9 solution made from $\mathrm{NH}_{4} \mathrm{NO}_{3}, \mathrm{KCl}$, and phosphoric acid $\left(\mathrm{H}_{3} \mathrm{PO}_{4}\right)$ with a density of $10.6 \mathrm{lbs} / \mathrm{gal}$.

Convert the $\mathrm{N}$ concentration of the 9-2-9 solution to a fraction

$$
\begin{aligned}
& 9 \% \mathrm{~N}=0.09 \mathrm{~N} \\
& \mathrm{~V}=(\mathrm{r} \times \mathrm{A} \times \mathrm{n}) /(\mathrm{c} \times \mathrm{d}) \\
& =(6 \mathrm{lb} / \mathrm{ac} \times 100 \mathrm{ac} \times 2) /(10.6 \mathrm{lb} / \mathrm{gal} \times 0.09) \\
& =1,258 \mathrm{gal}
\end{aligned}
$$

With 10\% additional storage for dead storage, the minimum needed volume of the tank should be 1,400 gallons.

\section{Equipment Installation and Maintenance}

To be serviceable, all equipment must be properly installed. Electrical installations should be in accordance with state and local codes. Only UL-approved equipment and materials developed for outdoor conditions should be used. Water and electricity are a potentially dangerous mixture.

All valve and pipe components must be pressure-rated to be able to withstand the high pressures of chemical injection. Chemicals and their concentrations must be compatible with the irrigation system materials. Storage tanks must be designed for the chemicals being used and must be properly located, installed, and maintained to guard against spillage.

Chemigation safety is more than the right equipment properly installed. The equipment requires regular maintenance. Many chemicals are highly corrosive. Corrosion-resistant components should be used and maintained by flushing with clean water between uses. All components should be checked before use and replaced before they become inoperable. 


\section{Chemical Safety}

Following chemical manufacturer's guidelines while mixing and using chemicals is essential to chemigation safety. In some instances, chemicals are added together to obtain a blend. It is important to know about the right order of mixing and follow the label instructions. Consider, for example, water and acid. Acid should always be added to water rather than adding water to acid. While mixing/handling the chemicals, appropriate clothing, gloves, and glasses should always be worn.

\section{Chemical Injection Methods}

There are several methods of chemical injection into an irrigation system. The choice of appropriate methods and equipment will depend on several factors. For injection of solid materials, agitation and mixing at pump site will be needed. Liquid fertilizers and agricultural chemicals, on the other hand, can be injected directly from their storage tanks. Injection of most fertilizer materials can normally be accomplished without high risks. However, when handling and injecting acids and toxic pesticides, worker safety is of great concern.

Some installations may require more than one injector because of vastly different flow rate requirements for the materials used. For instance, fertilizer injections are normally at a rate of at least $0.1 \%$ of the system flow rate. If the irrigation system delivers 1,000 gpm, the injection rate should be at least $1 \mathrm{gpm}$. The injection rate for acids, water conditioners, and some pesticides may be less than $10 \%$ of that for fertilizers, making it impossible to use the same injection device for both applications.

Sometimes, it is desirable to limit the amount of chemical that can be applied during an irrigation event. For instance, it may be advantageous to limit the amount of fertilizer so that a large over-application will not seriously damage or kill young trees. Other applicators may want to inject a specific volume each time, even though the run times or pressure may vary. Oftentimes the best way of limiting quantity applied is to use a larger storage or nurse tank to fill a smaller injection tank. With only a limited volume of chemical in the tank, it will be impossible to inject too much material, even if other safeguards fail. On electric pumps, controllers or timers can be used to limit the duration that injection pumps can operate. On water-powered pumps, volumetric controls can be used to shut the injection system off once a specified volume has been injected.

When installing a chemical injection system, it should be designed so that one can easily flush clean water through the injectors and fittings. Flushing after uses extends the life of most injectors. Frequent flushing helps maintain gaskets and metal components and may prevent encrustations from developing within the injector.

Normally, it is desirable to inject materials upstream of filters. The filters should trap any contaminants or precipitates that occur as a result of the injections. However, due to their corrosive effect, acids should normally be injected downstream of the filters. It is also necessary to discontinue injections during filter backwash cycles. On filter systems with automatic backwash controls, a controller should be installed to control both the backwash cycles and the injectors.

\section{Injectors}

Injection methods can be classified according to the method of operation. These methods include centrifugal pumps, positive displacement pumps (proportional injectors, rotary pumps, peristaltic pumps), pressure differential methods (suction line injection, discharge line injection, pressurized mixing tanks), and the use of the venturi principle. Some injectors use a combination of these methods.

\section{Centrifugal Pumps}

Small radial flow centrifugal pumps (booster pumps) can be used to inject chemicals into irrigation systems (Figure 8).

For a centrifugal pump to operate as an injector, it is necessary that the pressure produced by the pump be higher than the pressure in the irrigation line. However, the flow rate of the chemical from the pump depends on the pressure in the irrigation mainline. The higher the pressure, the smaller the flow rate from the injection pump. Therefore, centrifugal pumps require calibration while operating. 


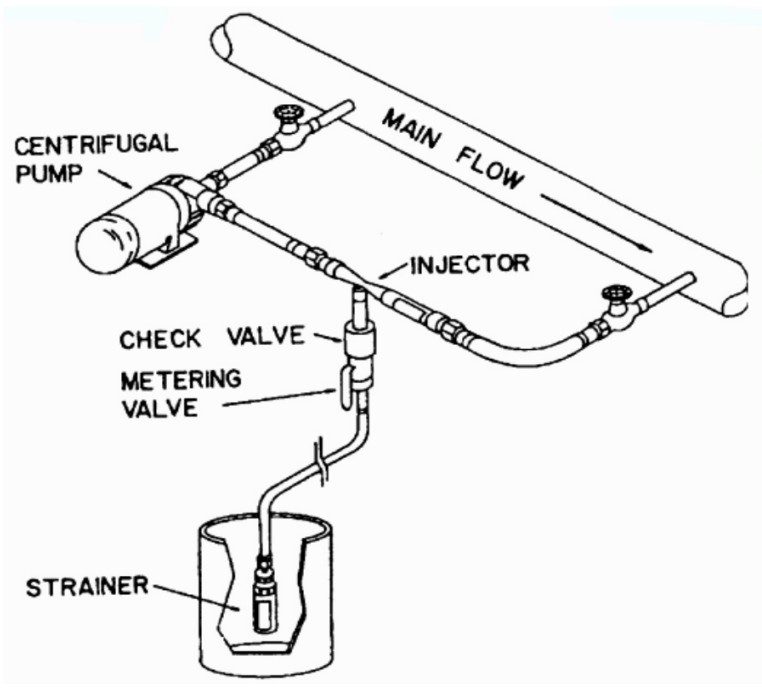

Figure 8. The use of a booster pump to create adequate pressure differential to operate a venturi for chemical injection.

It is not recommended that this type of pump be used when the injection rate must be very precisely controlled.

\section{Positive Displacement Pumps}

Positive displacement pumps are frequently used for injection of chemicals into a pressurized irrigation system. Positive displacement pumps displace a certain volume of liquid for each revolution of the pumping system. Generally, the volume of fluid pumped is independent of the pressure encountered at the discharge point. However, if the internal parts of the pump deform due to increased pressure (as in a mechanically-driven diaphragm pump), the displacement volume of the pump will change and the injection rate will not be constant. Excessive pressure at the discharge may also result in some back flow through the clearances of the pump parts (for example, between the gears and the housing in the gear pump).

Reciprocating pumps have a piston or a diaphragm that displaces a specific amount of solution with each stroke. The change in internal volume of the pump creates high pressure, which forces the solution into the discharge pipe. Piston, fluid-filled diaphragm, and piston/diaphragm pumps generally provide a constant flow rate independent of the discharge pressure. However, even with these pumps, excessive discharge pressure should be avoided (i.e., a closed valve in a discharge line), since it may result in pump damage.

The operation of a piston pump (Figure 9) is similar to the operation of the cylinder of an automobile engine. On an intake stroke, the solution enters the cylinder through the suction check valve. On a compression stroke, the solution is forced into the discharge line through the discharge check valve.

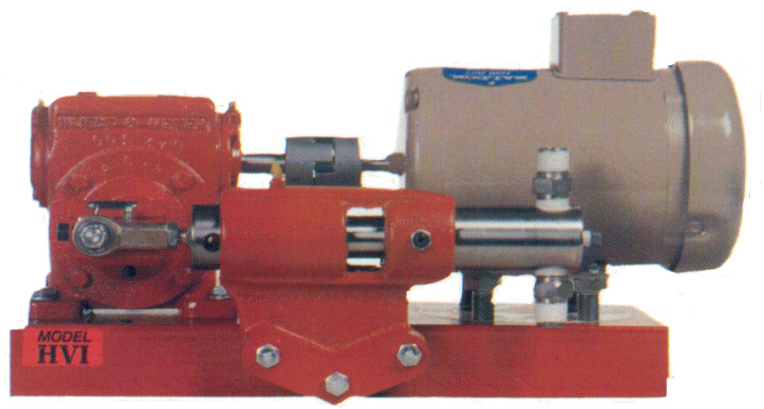

Figure 9. Piston injection pump.

The operation of a diaphragm pump (Figure 10) is similar to that of a piston pump. The pulsating motion is transmitted to the diaphragm through a fluid or a mechanical drive, and then through the diaphragm to the solution being injected.

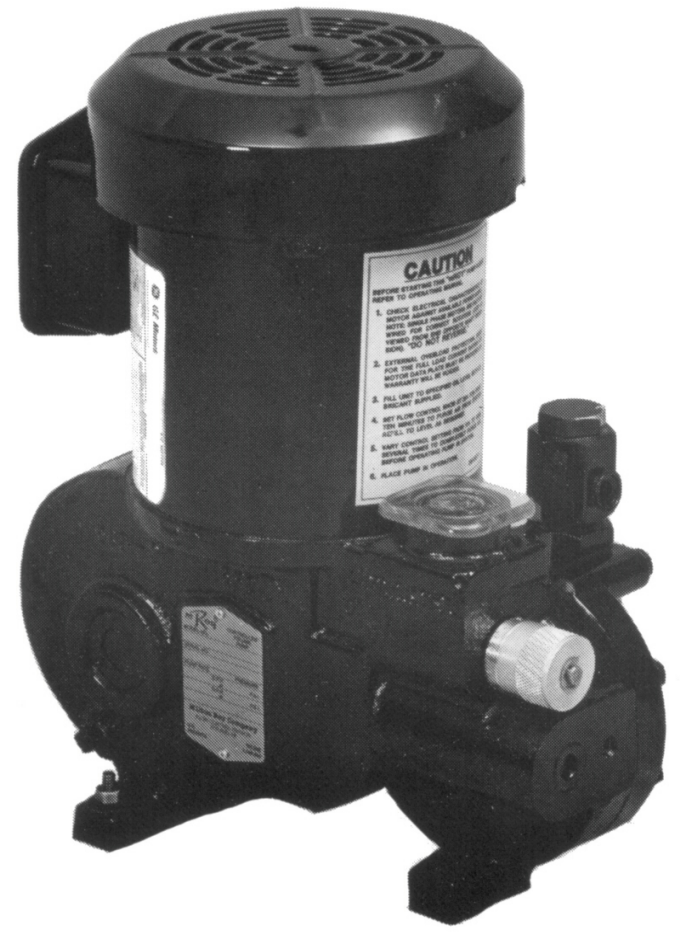

Figure 10. Diaphragm metering pump. 
Combination pumps usually contain a piston that forces oil or other fluid against a diaphragm which displaces the concentrated solution. The advantage of these pumps is that they combine the high precision of a piston pump with the resistance to chemicals of diaphragm pumps.

Reciprocating pumps are often electrically driven. The solution injection rate from an electrically-driven pump is approximately constant regardless of the water flow rate. Thus, the injection rate must be adjusted between zones if the flow rate to all zones is not constant.

\section{Proportional Injectors}

Proportional injectors utilize water flowing in the system to operate the injector (Figure 11). A volumetric hydraulic motor drives a volumetric dosing pump. The hydraulic motor is composed of a piston, the upper and lower faces of which are connected alternately to the inlet and outlet of the water supply via a fourvalve. The fourvalve is connected to an overdevice, actuated by two rods located on the piston stem. Therefore, the hydraulic motor moves up and down once every time the cylinder is filled (with a known volume). The dosing pump driven by the piston sucks up and injects the required volume of solution. The amount injected is adjusted by altering the free stroke of the dosing piston using the adjusting nut on the outside of the piston.

Piston and diaphragm pumps inject solutions in concentrated pulses separated in time. Some pumps are equipped with double-acting pistons or diaphragms to minimize variations in the concentration of chemicals in the irrigation system. If the length of pipe between the injection port and the first point of application is short, a blending tank should follow the injection to ensure adequate mixing of water and fertilizer.

\section{Rotary Pumps}

Rotary pumps transfer solution from suction to discharge through the action of rotating gears, lobes, or other similar mechanisms. Both gear and lobe type rotary pumps are sometimes used for chemical injection into irrigation systems. The operation of a

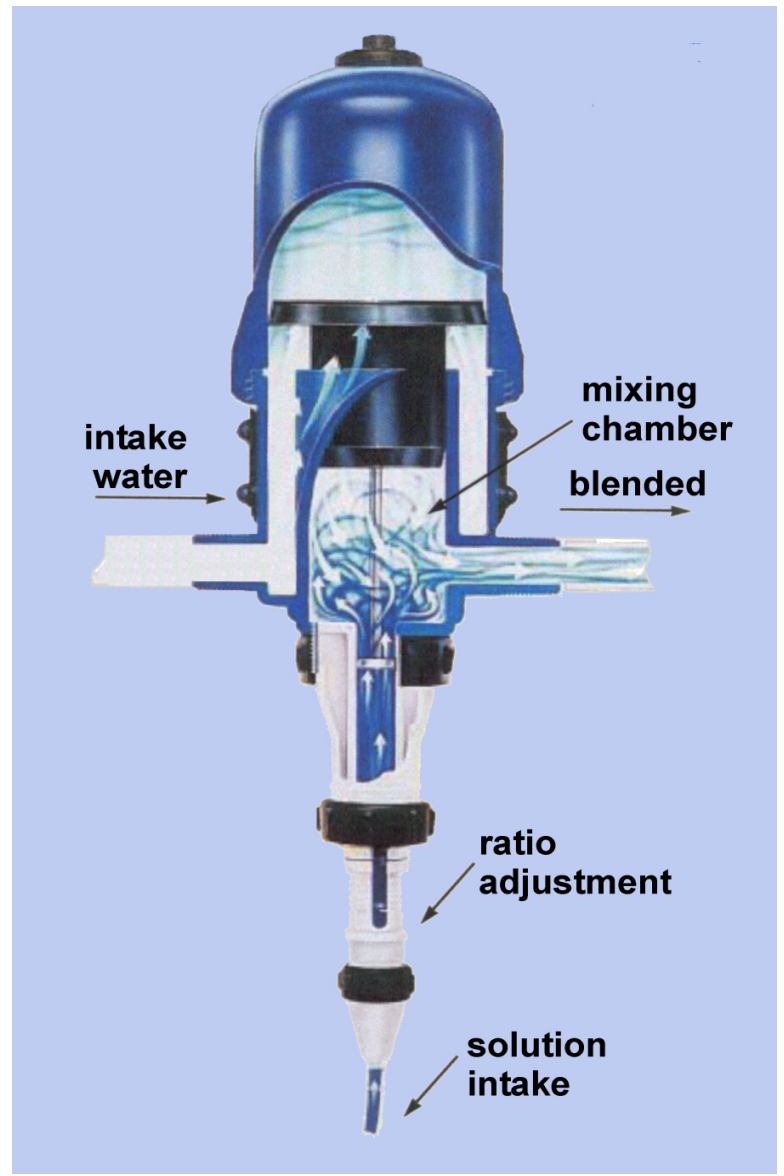

Figure 11. Action of water-driven proportional injector.

gear or lobe pump is based on the partial vacuum which is created by the enmeshing of the rotating gears (Figure 12) or lobes (Figure 13).

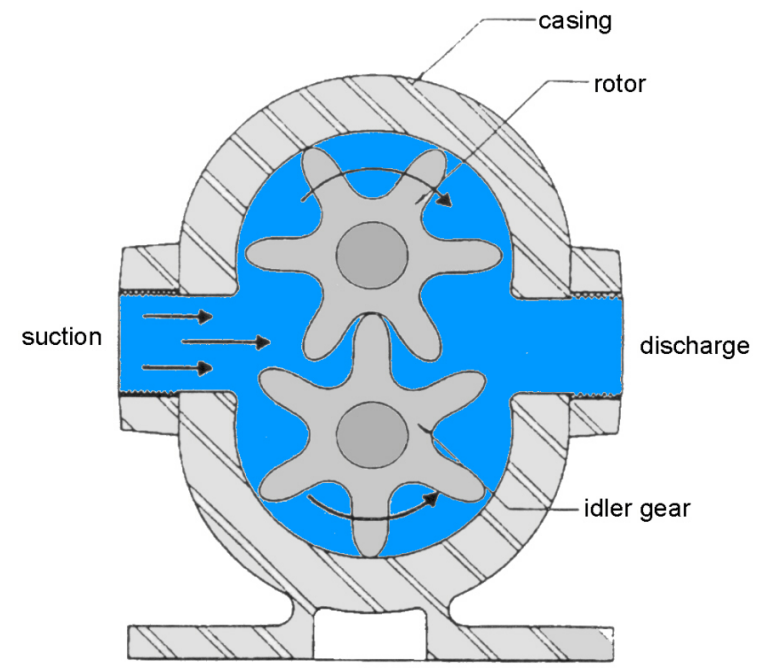

Figure 12. Gear injection pump.

This vacuum causes the solution to flow into the pump from where it is carried between the gears or lobes and the casing to the discharge side of the 


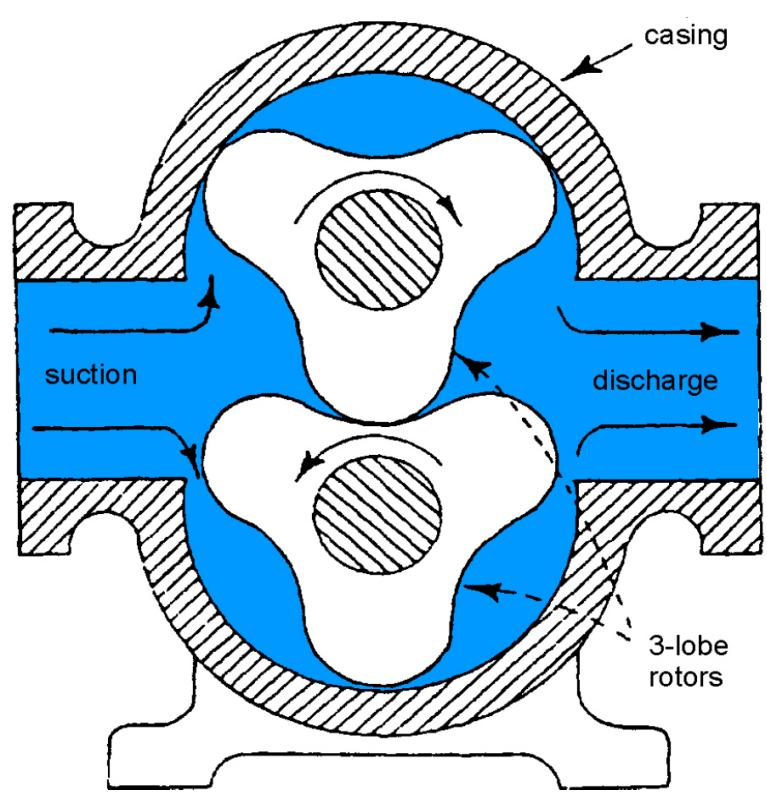

Figure 13. Lobe injection pump.

pump. Gear and lobe pumps produce approximately constant flow for a given rotor speed, and the injection rate does not change with flow rate in the irrigation system. Flow sensors can be used to assure a constant injection rate.

\section{Peristaltic Pumps}

Peristaltic pumps (Figure 14) are used mostly in chemical laboratories, but they can be used for injection of solutions into small irrigation systems. Their capacity is limited and most of them produce a pressure of only 30 to $40 \mathrm{psi}$. A flexible tube is pressed by a set of rollers, and even flow is produced by this squeezing action. The main advantage of these pumps is clean liners. The pump is suitable for pumping corrosive chemicals, since the pumped liquid is completely isolated from all moving parts of the pump.

\section{Pressure Differential Methods}

The pressure differential concept for injection is quite simple: If the pressure at the point of injection is lower than at the point of intake of the solution, the solution will flow into the line. There are several injection techniques which use this principle. They can be separated into two distinctive groups based on which side of the pump the injection takes place: suction side or discharge side.

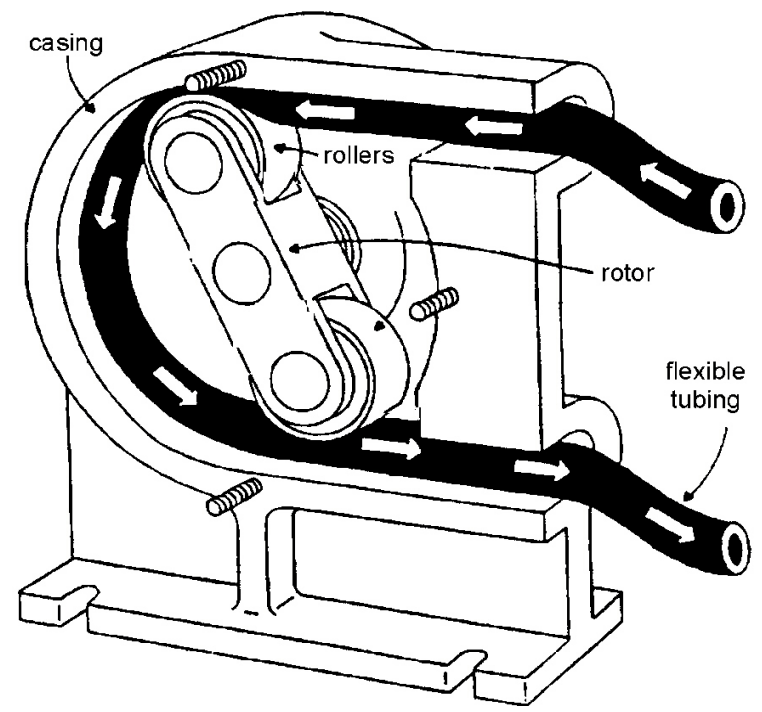

Figure 14. Peristaltic pump.

\section{Suction Line Injection}

The suction line injection technique can be used in irrigation systems using centrifugal pumps which are pumping water from the surface source such as a pond, lake, canal, or river. It is approved only for injection of fertilizer. Suction line injection is not permitted for irrigation systems pumping from wells.

This method requires minimum investment. The equipment necessary for this type of injection is a pipe or a hose, a few fittings, and an open container to hold the fertilizer solution (Figure 15). The rate of solution flow depends of the suction produced by the irrigation pump, the length and size of the suction line, and the level of solution in the supply tank. The injection rate can not be easily adjusted.

\section{Discharge Line Injection}

Discharge line injection requires a differential pressure to be created downstream of the pump. This is usually done by redirecting a portion of the main line flow through a chemical tank, while providing a pressure drop in the irrigation line. The pressure drop is accomplished by using some kind of restriction in the line, such as a valve, orifice, pressure regulator, or other device which would create a pressure drop. The use of valves allows for adjustment of the pressure drop, which also allows for some adjustment of the injection rate. 


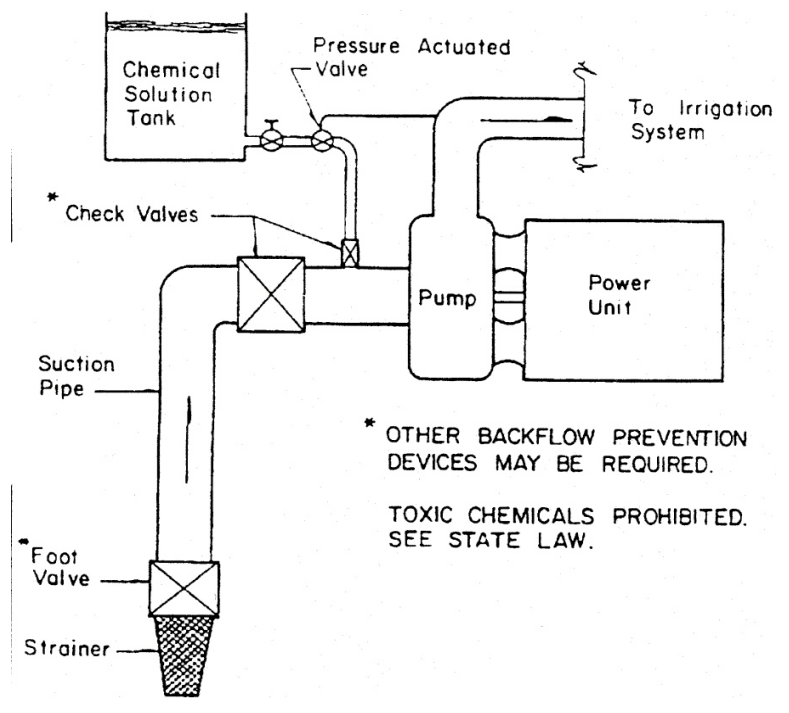

Figure 15. Injection on the suction line (legal only for fertilizer with surface water).

\section{Pressurized Mixing Tanks}

A mixing tank injector operates at the discharge line on a pressure differential concept. The water is diverted from the main flow, mixed with fertilizer, and injected or drawn back into the main stream of the system (Figure 16). A measured amount of fertilizer required for one injection is placed in the cylinder. The flow back into the main line is often controlled by a metering device installed on the inlet side of the injector. As the water enters the tank during injection, the concentration of the injection changes due to dilution of the chemical solution. To operate, there must be a pressure differential in the irrigation line between the inlet and outlet of the injector.

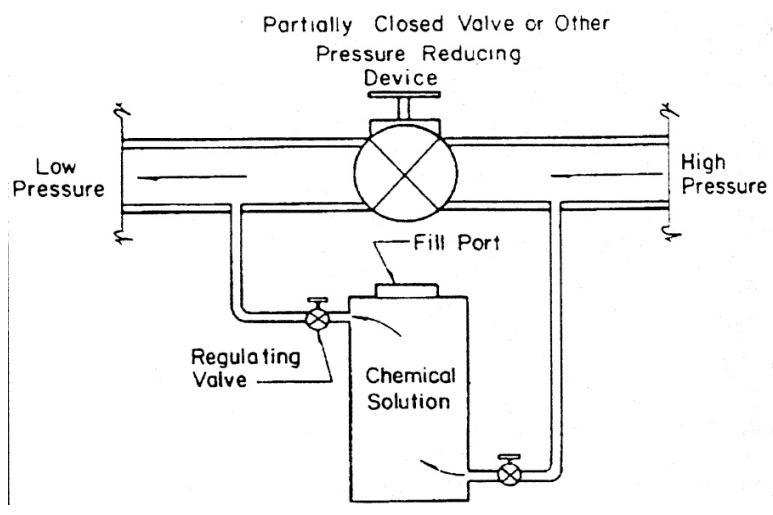

Figure 16. Pressurized mixing tank using a pressure reducing device to create pressure differential.

Proportional mixers are modifications of pressurized mixing tanks. They operate on the displacement principle. The chemical is placed in a collapsible bag which separates the solution from the water. Water pressure from the high pressure side forces the solution from the bag through the regulating valve into the mainline. As the solution flows out, the bag contracts and water on the outside of the bag displaces the volume. As long as the pressure and the flow rate in the system do not vary significantly, the injection rate will remain fairly constant. In systems where flow fluctuations can be expected, a proportioning control valve should be used. The proportioning valve responds to the changes of flow, not to pressure changes.

\section{Venturi Injector}

Chemicals can be injected into a pressurized pipe using the venturi principle. A venturi injector is a tapered constriction (Figure 17) which operates on the principle that a pressure drop results from the change in velocity of the water as it passes through the constriction.

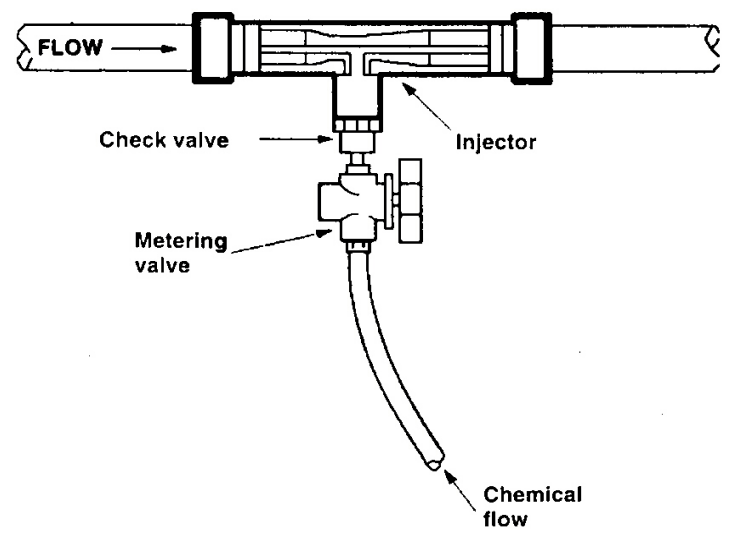

Figure 17. Venturi with metering valve suitable for chemical injection.

The pressure drop through a venturi must be sufficient to create a negative pressure (vacuum) relative to atmospheric pressure in order for the solution to flow from a tank into the injector.

A venturi injector does not require external power to operate. There are no moving parts, which increases its life and decreases probability of failure.

The injector is usually constructed of plastic, which makes it resistant to most chemicals. It requires minimal operator attention and maintenance, and its cost is low as compared to other equipment of 
similar function and capability. It is easy to adapt to most irrigation systems, provided a sufficient pressure differential can be created.

Venturi injectors come in various sized and can be operated under different pressure conditions. Suction capacity (injection rate), head loss required, and the range of working pressures will depend on the specific model. It is important to note that as the level in the supply tank drops, the injection rate decreases. To avoid this problem, some manufacturers utilize a small float-controlled injection tank located near the supply tank. A float valve in the line connecting to the supply tank maintains the level in the injection tank, thus a fairly constant injection rate can be achieved.

A small venturi can be used to inject small solution flow rates into a relatively large main line by shunting a portion of the flow through the injector (Figure 18).

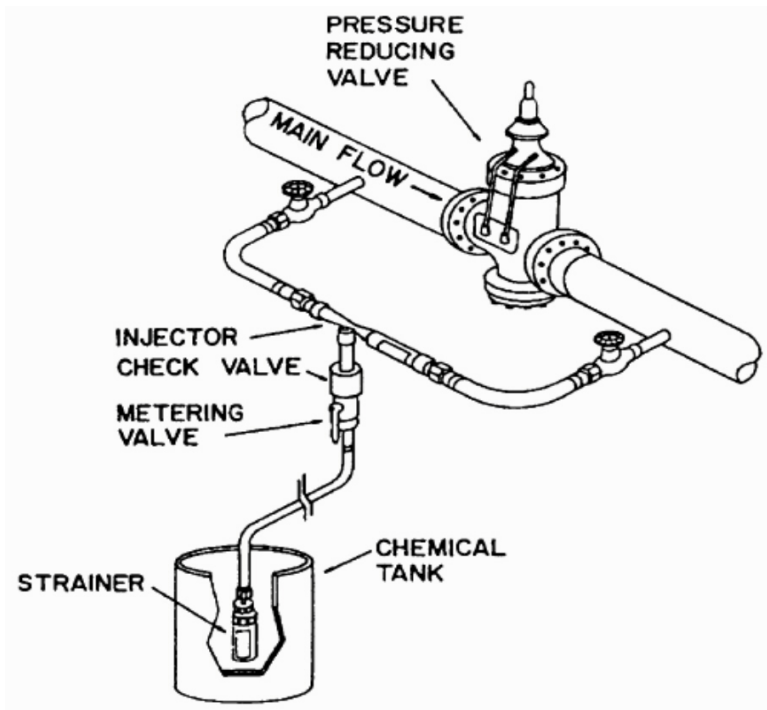

Figure 18. A small venturi in a bypass line used in conjunction with a pressure-reducing valve to inject agricultural chemicals.

To assure that the water will flow through the shunt, a pressure drop must occur in the main line. For this reason, the injector is used around a point of restriction such as a valve, orifice, pressure regulator, or other device which creates a differential pressure. A centrifugal pump, used to provide additional pressure in the shunt (Figure 19), can also be used.

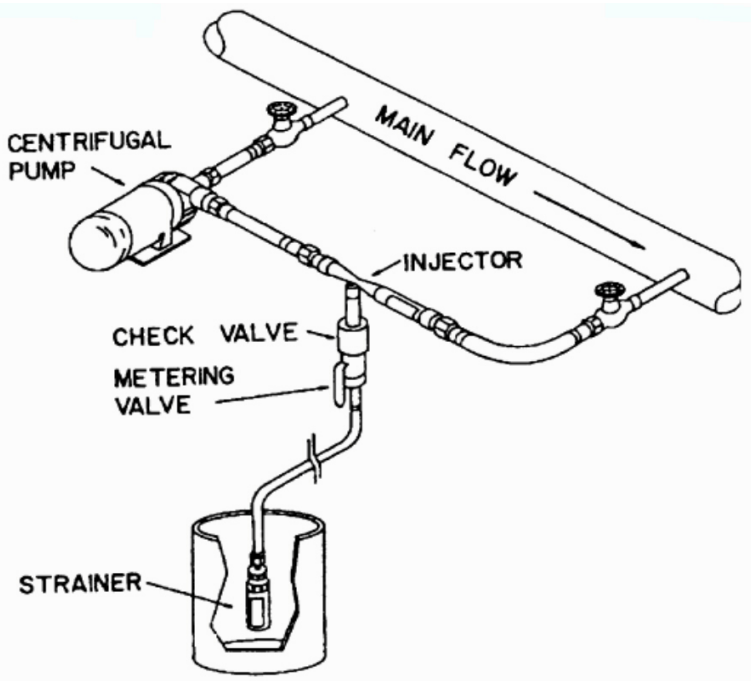

Figure 19. The use of a booster pump to create adequate pressure differential to operate a venturi for chemical injection.

Most venturi injectors require at least a $20 \%$ differential pressure to initiate a vacuum. A full vacuum of 28 inches of mercury is attained with a differential pressure of $5 \%$ or more. If there is only a small pressure differential in the irrigation pipeline, a large venturi can be used to create a pressure drop (Figure 20).

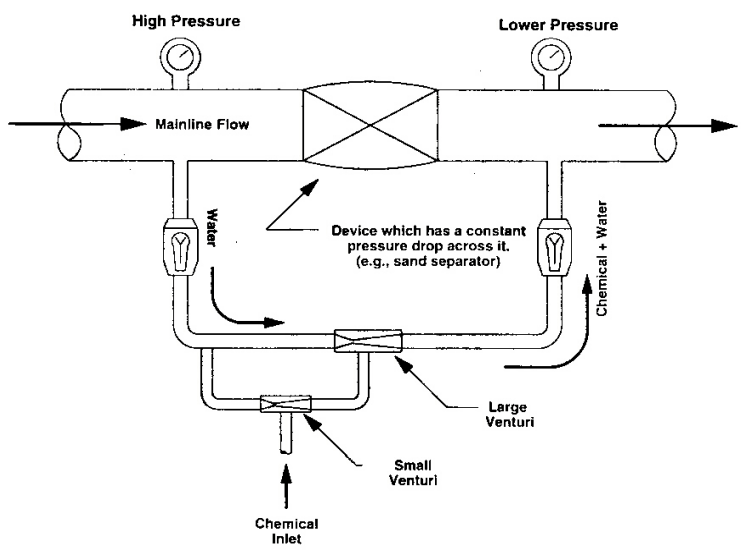

Figure 20. The use of a large venturi to create adequate pressure differential to operate a smaller venturi for chemical injection.

The large venturi can either be installed in the main line or in a bypass line. The pressure difference between the inlet and the throat of the large venturi can be used to inject chemicals in the smaller venturi. 


\section{Combination Methods}

There are some injectors on the market which employ combinations of the different principles of injection at the same time. The most common combination is a pressure differential combined with a venturi meter or some measuring device which uses the venturi principle.

Direct use of pressure differential in combination with a venturi can be found in some systems where the pressure drop required for a venturi may be difficult to provide due to design restrictions of the existing irrigation system. The combination of a venturi device with a pressurized chemical tank may be used in this case (Figure 21).

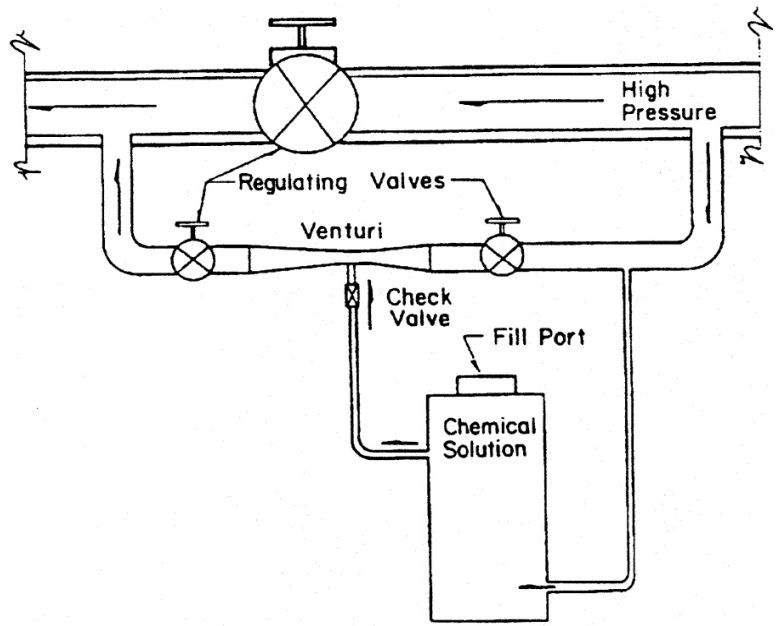

Figure 21. Combination of pressurized tank and venturi injector.

The chemicals are placed in the tank. Since the water flowing through the tank is under pressure, a sealed, airtight pressure supply tank constructed to withstand the maximum operating pressure is required. In this case, as the water enters the tank during injection, the injection rate will change gradually due to the change in solution concentration in the tank.

Various metering valves which are used with mixing and proportioning tanks operate on pressure or flow changes in the irrigation system. There are many designs of these valves. Frequently, it is some application of the venturi meter or the orifice with changing diameter. The manufacturer should be contacted for descriptions and operation instructions for various metering and proportioning valves.
Chemical injection on the suction side of a centrifugal pump is generally not permitted in Florida. The exception is a system which uses a surface water supply with only fertilizers being injected into the system. Florida backflow prevention law requires that a double protection of a check valve and a foot valve be used upstream of the injection port in this case.

According to the Environmental Protection Agency (EPA), only piston and diaphragm injection pumps can be used for pesticides and other toxic chemicals. Other methods can be used for injection of fertilizers or cleaning agents, such as chlorine or acids. Table 2 lists some of the advantages and disadvantages of the various types of injection devices.

\section{Calibration of Fertilizer Injection Systems}

Each method of fertilizer injection must be calibrated by the user. Calibration procedures vary depending upon the injection method used and the specific design of the injection equipment. The user must verify that the manufacturer's calibration or the method being used is correct. This can be achieved by using a chemical flow meter, which is accurate in the flow range of gallons per hour (or other rate being injected), or by volumetric measurement of the injection rate.

\section{Chemical Flow Meters}

Flow meters (Figure 22) are available which can be used to directly measure the solution flow rate, while the injection system is operating under field conditions.

Meters can often be mounted on the low pressure (suction) side of injection pumps. If a chemical flow meter is used on the high pressure side of an injector, be certain that the flow meter is rated for the pressure being used before installing it in that position. Failure to use a properly installed, adequately pressure-rated meter may cause it to be damaged, which may be hazardous to individuals working in the area. 


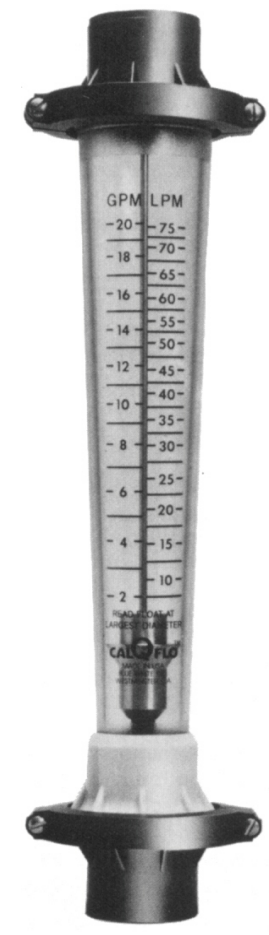

Figure 22. Rotameter with stainless steel float suitable for flow measurement of fertilizer solutions.

\section{Volumetric Flow Rate Measurement}

To measure flow rates volumetrically, a container of known volume (such as a graduated cylinder) and a stopwatch or other accurate timer is needed. Measure the time required to fill the container. Then calculate the flow rate by dividing the volume with time elapsed. Typically the units used are gallons per hour (gal/hr or gph).

\section{Example:}

Assume that a 100-ml graduated cylinder and stopwatch were used to measure injection rates. If 90 $\mathrm{ml}$ of fertilizer solution could be collected in 4 minutes and 3 seconds, calculate the injection rate in gph.

$$
\begin{aligned}
& 1 \mathrm{gal}=3,785 \mathrm{ml} \text {. } \\
& 90 \mathrm{ml}=90 / 3,785 \mathrm{gal}=0.0238 \mathrm{gal} \\
& 1 \mathrm{hr}=3,600 \mathrm{sec} . \\
& 4 \mathrm{~min}, 30 \mathrm{sec}=270 \mathrm{sec}=270 / 3,600=0.075 \mathrm{hr} \text {. } \\
& \text { Injection rate }=0.0238 \mathrm{gal} / 0.075 \mathrm{hr}=0.32 \mathrm{gal} / \mathrm{hr}
\end{aligned}
$$

For many injection methods, the injection rate will decrease as system pressure increases. Therefore, the calibration procedure should be done on each zone while the system is operating at typical pressure and flow rates. It is always a good idea to measure the rate of fertilizer removal from the storage tank to provide a check on calibration. The drop in the tank level over a specific time period (typically 1 hour) can be measured to verify injection rate.

\section{Example:}

The level in a 12-ft diameter vertical supply tank drops 10 inches during a 1 hour injection period. Determine the injection rate (gph).

Calculate the volume $\left(\mathrm{ft}^{3}\right)$ of liquid removed from tank.

Convert depth of 10 inches to feet: 10 inches/12 inches $/ \mathrm{ft}=0.83 \mathrm{ft}$.

For $12 \mathrm{ft}$ diameter $(\mathrm{d})$ tank the area $=(3.14 \mathrm{x}$ $\left.\mathrm{d}^{2}\right) / 4=\left(3.14 \times 12^{2}\right) / 4=113 \mathrm{ft}^{2}$. $=93.8 \mathrm{ft}^{3}$.

Volume $=$ area $\times$ drop height $=113 \mathrm{ft}^{2} \times 0.83 \mathrm{ft}$

Convert to gallons (7.5 gallons per $\mathrm{ft}^{3}$ ).

Volume $=93.8 \mathrm{ft}^{3} \times 7.5 \mathrm{gal} / \mathrm{ft}^{3}=704 \mathrm{gal} ;$

Injection rate $=704 \mathrm{gal} / \mathrm{hr}$.

\section{Example:}

The initial level in a 5-ft diameter $\mathrm{x} 8$-ft-long horizontal supply tank is 38 inches from the bottom. After 1 hour, the level has fallen to 28 inches. Determine the injection rate.

Calculate the total volume of the tank.

$$
\begin{aligned}
& \text { Area }=\left(3.14 \times \mathrm{d}^{2}\right) / 4=\left(3.14 \times 5^{2}\right) / 4=19.6 \mathrm{ft}^{2} . \\
& \text { Volume }=\text { area } \times \text { length }=19.6 \mathrm{ft}^{2} \times 8 \mathrm{ft}=157 \mathrm{ft}^{3} \text {. } \\
& \text { Convert to gallons }\left(7.5 \mathrm{gal} \text { per } \mathrm{ft}^{3}\right) . \\
& \text { Volume }=157 \mathrm{ft}^{3} \times 7.5 \mathrm{gal} / \mathrm{ft}^{3}=1178 \text { gal. } \\
& \text { Refer to Table } 3 \text { and Figure } 23 \text { to calculate } \\
& \text { volume in a partially filled horizontal cylindrical } \\
& \text { tank. Total depth }=5 \mathrm{ft} \times 12 \mathrm{in} / \mathrm{ft}=60 \text { in. }
\end{aligned}
$$


Initial volume:

Initial TD $($ percentage of total tank diameter $)=$ $(38 \text { in } / 60 \text { in })^{*} 100=63 \%$

From Table 3 corresponding TC (for TD of $63 \%)=66.39 \%$

Initial volume $=1,178$ gal x $66.39 \%=782 \mathrm{gal}$

$\underline{\text { Final Volume }}$

$\mathrm{TD}=(28 \mathrm{in} / 60 \mathrm{in}) * 100=47 \%$

From Table 3 for $\mathrm{TD}=47 \%, \mathrm{TC}=46.19 \%$

Final volume $=1,178$ gal x $46.19 \%=544$ gal

Volume injected $=$ Initial volume - Final volume $=782-544=238$ gal.

Injection rate $=238 \mathrm{gph}$ or about $4.0 \mathrm{gpm}$.

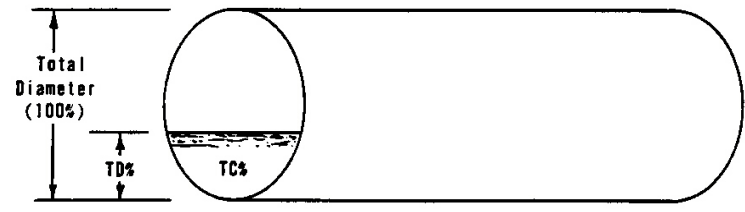

Figure 23. Factors for calculating approximate gallons contained in partially filled horizontal cylindrical tanks with flat ends, where TD = Filled percentage of total tank diameter, and TC $=$ Percent of total tank capacity.

It is a good idea to inject fertilizers from a small, graduated supply tank rather than to pump directly from a large bulk storage tank. The small tank should be sized to contain the fertilizer solution for one application, and only this amount should be placed in the small tank before irrigation. This procedure can improve the effectiveness of fertilizer in the small supply tank, thus preventing accidental applications of excess fertilizer. The amount of fertilizer injected can be read easily and accurately if the supply tank is relatively small, and has graduations permanently marked on it. Another benefit is that only the fertilizer in the small tank will be diluted, if backflow from the irrigation system occurs from failure of the injection pump and backflow prevention system.

For injection methods which use a suction tubing between the injection pump and the supply tank, the injection rate can be measured with a solution flow meter, or by connecting the tubing to a graduated cylinder. Measurements should be made while the injector is operating under normal conditions, including normal injection rates and normal irrigation systems operating pressures. Then, adjustments in the injection rate can be made as the injection system operates.

\section{Calculating Fertilizer Injection Rates}

For all methods of injection, the required fertilizer injection rate must be known. The required injection rate can be calculated from the following equations for microsprinkler systems.

The fertilizer injection rate in gallons per hour (gph) is calculated from:

$$
\text { Rate }=(100 \times \mathrm{A} \times \mathrm{F}) /(\mathrm{P} \times \mathrm{H} \times \mathrm{D}) \mathrm{Eq} .2
$$

where:

Rate $=$ fertilizer injection rate $(\mathrm{gph})$,

$A=$ area to be irrigated $(\mathrm{ac})$,

$\mathrm{F}=$ fertilizer amount to be applied per acre (lb/ac),

$\mathrm{P}=$ fertilizer fraction, percent of fertilizer per gal of fluid injected (\%),

$\mathrm{H}=$ fertilizer injection time $(\mathrm{hr})$,

$\mathrm{D}=$ density of the fertilizer solution (lb/gal),

\section{Example:}

Assume that $8 \mathrm{lb}$ per acre of nitrogen is applied to a 75-acre citrus block using a microsprinkler system. The fertilizer to be used is a $10-0-10$ solution that weighs $10.5 \mathrm{lb} / \mathrm{gal}$. The irrigation cycle is $4 \mathrm{hr}$, and fertilizer injection begins 1 hour after the system has reached normal operating pressure. Fertilizer will be injected for $2 \mathrm{hr}$, leaving $1 \mathrm{hr}$ to flush the fertilizer from the irrigation system. Calculate the injection rate for the above condition.

Rate $=(100 \times 75 \mathrm{ac} \times 8 \mathrm{lb} / \mathrm{ac}) /(10 \% \times 2.0 \mathrm{hr} \times$ $10.5 \mathrm{lb} / \mathrm{gal})=286 \mathrm{gph}$.

The required $8 \mathrm{lb} / \mathrm{ac}$ of $\mathrm{N}$ can be applied by injecting 286 gal of $10-0-10$ fertilizer per hour for the 
$2.0 \mathrm{hr}$ injection time. Total volume to be injected $=$ $286 \mathrm{gal} / \mathrm{hr} \times 2.0 \mathrm{hr}=572$ gallons.

It is important to note that microsprinkler irrigation systems do not irrigate the entire soil surface, and the fertilizers applied using these systems will be delivered only to the irrigated portion of the soil surface. For example, if only $50 \%$ of the soil surface is irrigated with the spray system, the $\mathrm{N}$ application rate in the irrigated zone for the example problem will be $16 \mathrm{lb} / \mathrm{ac}$, and that in the non-irrigated zone will be $0 \mathrm{lb} / \mathrm{ac}$. Likewise, if only $20 \%$ of the soil surface is irrigated, the application rate in the irrigated area would be 5 times the average on a gross acre basis. Because water and fertilizers are not applied to the entire soil surface when microirrigation systems are used, fertilizer applications to micro-irrigated crops are often made on the basis of individual plants, rather than on a gross acre basis. In this case, the following equation can be used:

Rate $=\left(100 \times\right.$ A $\times F_{p} \times$ NP $) /(P \times H \times$ D $)$ Eq. 3

where: (lb/plant),

$\mathrm{F}_{\mathrm{p}}=$ amount of fertilizer to be applied per plant

$\mathrm{NP}=$ number of plants per acre,

Rate $=$ fertilizer injection rate $(\mathrm{gph})$,

$\mathrm{A}=$ area to be irrigated $(\mathrm{ac})$,

$\mathrm{P}=$ fertilizer injection time (hr) and,

$\mathrm{D}=$ density of fertilizer solution (lb/gal).

\section{Example:}

Assume that $0.05 \mathrm{lb}$ of $\mathrm{N}$ (from an 8-0-8 solution with density of $10.4 \mathrm{lb}$ per gal) is to be applied to each tree in a 40-acre grove of young citrus trees with 151 trees per acre. The irrigation system is operated for a total of $3 \mathrm{hr}$ per irrigation. After startup of the irrigation system, fertilizer is injected for $2 \mathrm{hr}$, followed by almost 1 hour of irrigation to flush the fertilizer from the system.

Rate $=(100 \times 40$ ac $\times 0.05 \mathrm{lb} /$ tree $\times 151$ tree/ac)/(8\% x 2 hr x 10.4 lb/gal) - 182 gph.
Thus, the required $0.05 \mathrm{lb}$ of $\mathrm{N}$ per tree can be applied to 40 acres by injecting 182 gph for the $2 \mathrm{hr}$ of fertilizer injection time. Total volume to be injected $=182 \mathrm{gal} / \mathrm{hr} \times 2 \mathrm{hr}=362 \mathrm{gal}$.

\section{References}

Burt, C., K. O'Connor, and T. Ruehr. 1998. Fertigation. San Luis Obispo, CA: Irrigation Training and Research Center, California Polytechnic State University. 
Table 1. Descriptions of required safety devices for chemical injection.

\begin{tabular}{||l|l|l||}
\hline \hline \multicolumn{1}{|c|}{ Device } & \multicolumn{1}{|c|}{ Description/Location } & \multicolumn{1}{c||}{ Purpose } \\
\hline Irrigation check valve & Between well and injection points & $\begin{array}{l}\text { Prevents chemicals from flowing } \\
\text { backwards and entering the water } \\
\text { source }\end{array}$ \\
\hline Injection line check valve & $\begin{array}{l}\text { At the injection point. It is a one-way } \\
\text { valve with a 10 psi spring which } \\
\text { closes when not under pressure }\end{array}$ & $\begin{array}{l}\text { Prevents water from flowing } \\
\text { backwards into the chemical tank, } \\
\text { which would cause the tank to } \\
\text { overflow and spill }\end{array}$ \\
\hline Vacuum relief valve & Between check valve and well & $\begin{array}{l}\text { Prevents vacuum when pump shuts } \\
\text { off and reduces chance of backflow }\end{array}$ \\
\hline Low pressure cutoff & On irrigation pipeline & $\begin{array}{l}\text { Turns off injector power when } \\
\text { irrigation water pressure is low }\end{array}$ \\
\hline Low pressure drain & $\begin{array}{l}\text { Between well and irrigation line check } \\
\text { valve }\end{array}$ & $\begin{array}{l}\text { Discharges any water which might } \\
\text { leak through the check valve after } \\
\text { irrigation pump is shut off }\end{array}$ \\
\hline Normally closed solenoid valve & $\begin{array}{l}\text { Between injection pump and chemical } \\
\text { tank }\end{array}$ & $\begin{array}{l}\text { Prevents tank from emptying unless } \\
\text { injector is working }\end{array}$ \\
\hline Interlock & Between injection pump and irrigation & $\begin{array}{l}\text { Prevents injection if irrigation pump } \\
\text { stops }\end{array}$ \\
\hline \hline
\end{tabular}

Table 2. Comparison of various chemical injection methods.

\begin{tabular}{||l|l|l||}
\hline \hline \multicolumn{1}{||c|}{ Injector } & \multicolumn{1}{c|}{ Advantages } & \multicolumn{1}{c||}{ Disadvantages } \\
\hline Centrifugal pump & $\begin{array}{l}\text { Low cost } \\
\text { Can be adjusted while running }\end{array}$ & Calibration depends on system pressure \\
\hline Piston pump & $\begin{array}{l}\text { Very high pressure } \\
\text { High precision } \\
\text { Linear calibration } \\
\text { Calibration independent of pressure }\end{array}$ & $\begin{array}{l}\text { High cost } \\
\text { May need to stop to adjust calibration } \\
\text { Chemical flow not continuous }\end{array}$ \\
\hline Diaphragm pump & $\begin{array}{l}\text { Can adjust calibration while } \\
\text { injecting } \\
\text { High chemical resistance }\end{array}$ & $\begin{array}{l}\text { Non-linear calibration } \\
\text { Calibration depends on system pressure } \\
\text { Chemical flow not continuous } \\
\text { Medium to high cost }\end{array}$ \\
\hline $\begin{array}{l}\text { Piston/diaphragm } \\
\text { pump }\end{array}$ & $\begin{array}{l}\text { High precision } \\
\text { Linear calibration } \\
\text { Very high pressure } \\
\text { Calibration independent of pressure } \\
\text { High precision }\end{array}$ & $\begin{array}{l}\text { High cost } \\
\text { May need to stop to adjust calibration }\end{array}$ \\
\hline \hline
\end{tabular}


Table 2. Comparison of various chemical injection methods.

\begin{tabular}{|c|c|c|}
\hline Injector & Advantages & Disadvantages \\
\hline Gear and lobe pumps & $\begin{array}{l}\text { Injection rate can be adjusted when } \\
\text { running }\end{array}$ & $\begin{array}{l}\text { Fluid pumped cannot be abrasive } \\
\text { Injection rate is dependent on system pressure } \\
\text { Continuity of chemical flow depends on number of } \\
\text { lobes in lobe pump }\end{array}$ \\
\hline Peristaltic pump & $\begin{array}{l}\text { High chemical resistance } \\
\text { Major adjustments can be made by } \\
\text { changing tubing size } \\
\text { Injection rate can be adjusted while } \\
\text { running }\end{array}$ & $\begin{array}{l}\text { Short tube life expectancy } \\
\text { Injection rate dependent on system pressure } \\
\text { Low to medium injection pressure }\end{array}$ \\
\hline Suction line port & $\begin{array}{l}\text { Very low cost } \\
\text { Injection rate can be adjusted while } \\
\text { running }\end{array}$ & $\begin{array}{l}\text { Permitted only for surface water source with } \\
\text { injection of fertilizer } \\
\text { Injection rate depends on main pump operation }\end{array}$ \\
\hline Proportional mixers & $\begin{array}{l}\text { Low to medium cost } \\
\text { Calibrate while operating } \\
\text { Injection rates accurately controlled }\end{array}$ & $\begin{array}{l}\text { Pressure differential required } \\
\text { Volume to be injected is limited by size of injector } \\
\text { Frequent refills required }\end{array}$ \\
\hline $\begin{array}{l}\text { Pressurized mixing } \\
\text { tanks }\end{array}$ & $\begin{array}{l}\text { Medium cost } \\
\text { Easy operation } \\
\text { Total chemical volume accurately } \\
\text { controlled }\end{array}$ & $\begin{array}{l}\text { Pressure differential required } \\
\text { Variable chemical concentration } \\
\text { Cannot be calibrated for constant injection rate }\end{array}$ \\
\hline Venturi & $\begin{array}{l}\text { Low cost } \\
\text { Water powered } \\
\text { Simple to use } \\
\text { Calibrate while operating } \\
\text { No moving parts }\end{array}$ & $\begin{array}{l}\text { Pressure drop created in system } \\
\text { Calibration depends on solution level in tank }\end{array}$ \\
\hline $\begin{array}{l}\text { Combination } \\
\text { proportion mixers } \\
\text { venturi injectors }\end{array}$ & $\begin{array}{l}\text { Greater precision than proportional } \\
\text { mixer or venturi alone }\end{array}$ & $\begin{array}{l}\text { Higher cost than proportional mixer or venturi } \\
\text { alone }\end{array}$ \\
\hline
\end{tabular}

Table 3. Approximate gallons contained in partially filled horizontal cylindrical tanks (flat ends), where: TD = Filled percentage of total tank diameter, and TC = Percent of total tank capacity. TD\% = fluid depth/tank depth $\times 100$. Volume in tank $=$ TC\% $\mathrm{x}$ total tank volume (in gallons).

\begin{tabular}{|r|c|c|c|c|c|c|c|c|c||}
\hline \hline TD & TC & TD & TC & TD & TC & TD & TC & TD & TC \\
\hline 0 & 0.0000 & 20 & 14.24 & 40 & 37.36 & 60 & 62.65 & 80 & 85.76 \\
1 & 0.1692 & 21 & 15.27 & 41 & 38.60 & 61 & 63.89 & 81 & 86.77 \\
2 & 0.4773 & 22 & 16.31 & 42 & 39.86 & 62 & 65.13 & 82 & 87.76 \\
3 & 0.8742 & 23 & 17.38 & 43 & 41.12 & 63 & 66.39 & 83 & 88.73 \\
4 & 1.342 & 24 & 18.46 & 44 & 42.38 & 64 & 67.59 & 84 & 89.67 \\
5 & 1.869 & 25 & 19.55 & 45 & 43.64 & 65 & 68.81 & 85 & 90.59 \\
6 & 2.450 & 26 & 20.66 & 46 & 44.91 & 66 & 70.02 & 86 & 91.49 \\
7 & 3.077 & 27 & 21.79 & 47 & 46.19 & 67 & 71.22 & 87 & 92.36 \\
8 & 3.748 & 28 & 22.92 & 48 & 47.46 & 68 & 72.41 & 88 & 93.20 \\
9 & 4.458 & 29 & 24.07 & 49 & 48.73 & 69 & 73.59 & 89 & 94.02 \\
10 & 5.204 & 30 & 25.23 & 50 & 50.00 & 70 & 74.77 & 90 & 94.80 \\
11 & 5.985 & 31 & 26.41 & 51 & 51.27 & 71 & 75.93 & 91 & 95.54 \\
\hline \hline
\end{tabular}


Table 3. Approximate gallons contained in partially filled horizontal cylindrical tanks (flat ends), where: TD = Filled percentage of total tank diameter, and TC $=$ Percent of total tank capacity. TD\% $=$ fluid depth/tank depth $\times 100$. Volume in tank $=$ TC $\% x$ total tank volume (in gallons).

\begin{tabular}{|r|l|r|r|r|r|r|r|r|r|r|r||}
\hline \hline TD & TC & TD & TC & TD & TC & TD & TC & TD & TC \\
\hline 12 & 6.797 & 32 & 27.59 & 52 & 52.54 & 72 & 77.08 & 92 & 96.25 \\
13 & 7.639 & 33 & 28.78 & 53 & 53.81 & 73 & 78.22 & 93 & 96.92 \\
14 & 8.509 & 34 & 29.98 & 54 & 55.09 & 74 & 79.34 & 94 & 97.55 \\
15 & 9.406 & 35 & 31.19 & 55 & 56.36 & 75 & 80.45 & 95 & 98.13 \\
16 & 10.33 & 36 & 32.41 & 56 & 57.62 & 76 & 81.54 & 96 & 98.66 \\
17 & 11.27 & 37 & 33.64 & 57 & 58.88 & 77 & 82.62 & 97 & 99.13 \\
18 & 12.24 & 38 & 34.87 & 58 & 60.14 & 78 & 83.69 & 98 & 99.52 \\
19 & 13.23 & 39 & 36.11 & 59 & 61.40 & 79 & 84.73 & 99 & 99.83 \\
\hline \hline
\end{tabular}

